\title{
Analysis of disseminated tumor cells before and after platinum based chemotherapy in primary ovarian cancer. Do stem cell like cells predict prognosis?
}

\author{
Issam Chebouti1,*, Christina Blass| ${ }^{2, *}$, Pauline Wimberger ${ }^{3}$, Hans Neubauer ${ }^{2}$, \\ Tanja Fehm², Rainer Kimmig ${ }^{1}$, Sabine Kasimir-Bauer ${ }^{1}$ \\ ${ }^{1}$ Department of Gynecology and Obstetrics, University Hospital Essen, Essen, Germany \\ ${ }^{2}$ Department of Gynecology and Obstetrics, University Hospital Düsseldorf, Düsseldorf, Germany \\ ${ }^{3}$ Department of Gynecology and Obstetrics, Carl-Gustav-Carus University, TU Dresden, Dresden, Germany \\ *These authors have contributed equally to this work
}

Correspondence to: Issam Chebouti, e-mail: Issam.Chebouti@uk-essen.de

Keywords: disseminated tumor cells, bone marrow, stem cells, primary ovarian cancer

Received: December 02, 2015

Accepted: February 21, 2016

Published: April 01, 2016

\section{ABSTRACT}

Background: We recently reported that the presence of disseminated tumor cells (DTCs) in the bone marrow (BM) of primary ovarian cancer patients (POC pts) correlated with reduced progression free survival (PFS) and overall survival (OS). Here we analyzed whether the negative prognostic influence was related to DTC persistence after platinum based chemotherapy and/or due to DTCs associated with stem cell character.

Results: DTCs were detected in 33/79 pts (42\%) before and in $32 / 79$ pts (41\%) AT. Persistent DTCs were found in 13 pts, 20 pts were only positive BT, 19 pts AT and 27 pts had no DTCs. Whereas the presence of DTCs BT significantly correlated with reduced OS $(p=0.02)$, pts initially DTC ${ }_{\text {neg }}$ BT but DTC ${ }_{\text {pos }}$ AT had a significantly shorter PFS $(p=0.03)$. DTC persistence resulted in a shorter PFS and OS reaching borderline significance $(p=0.06 ; p=0.07)$. LIN-28-and SOX-2 positive cells were detected in all eight pts AT.

Patients and Methods: 79 POC pts were studied for DTCs before therapy (BT) and after therapy (AT) using immunocytochemistry. Eight pts harboring at least five DTCs AT were further analyzed on two additional slides by four-fold immunofluorescence staining for DAPI, Cytokeratin (CK), SOX-2 or LIN-28, CD45 and CD34 (Cy5). A stem-like tumor cell was classified as Dapi $_{\text {pos, }}$ CD45 ${ }_{\text {neg, }}$ CD34 ${ }_{\text {neg, }}$ SOX-2 pos $/$ LIN-28 pos $_{\text {and }}$ and $\mathrm{CK}_{\text {pos }}$ or $\mathrm{CK}_{\text {neg. }}$.

Conclusions: Stem cell associated proteins are expressed in DTCs that are present AT and their presence seem to be correlated with a worse outcome. Additional therapeutic regimens may be necessary to eliminate these cells.

\section{INTRODUCTION}

Ovarian cancer is the fifth leading cause of all cancer related deaths in Europe and the United States and most tumors are diagnosed in an advanced stage with poor prognosis for the patients [1]. Conventional therapy is based on an initial debulking surgery aiming at macroscopic complete resection combined with subsequent platinum- and paclitaxel -based chemotherapy [2]. Postoperative residual tumor is one of the most important prognostic factors in advanced ovarian cancer $[3,4,5]$.

It is hypothesized that cancer malignancy and metastasis are driven by a small subgroup of highly tumorigenic cells within the tumor, called metastasis initiating cells (MIC). These cells have the ability to self-renew, enhance tumorigenesis and are often found to be drug resistant [6]. The presence of such a small 
population, often referred to as cancer stem cells (CSC), has been confirmed in ovarian cancer cell lines as well as in tumor tissue $[7,8]$. Their amount is increased in chemotherapy resistant ovarian cancer cell lines [7] and they are believed to contribute to an aggressive behavior of epithelial ovarian cancer [9]. The pluripotency associated stem cell factors SOX2 (sry related) and LIN-28 have been found to be expressed in ovarian cancer cell lines and tissue $[10,11,12]$. Bareiss et al., showed that $\mathrm{SOX} 2$ expression is a CSC marker in serous ovarian carcinomas (SOC) and can induce CSC properties [11]. In addition, SOX2 was reported to enhance migration and invasion of ovarian cancer cells [13]. Importantly, SOX2 overexpression was shown to be a poor prognostic marker in ovarian cancer [14] and also shown to be involved in taxane resistance $[15,16]$.

In ovarian cancer, the primary tumor usually metastasizes to the peritoneum, but a variety of studies including ours indicate that tumor cells frequently disseminate into the bone marrow (BM). Disseminated tumor cells (DTCs) in the BM are detected in $20 \%$ to $60 \%$ of cases before the onset of platinum-based chemotherapy depending on the method of detection used. Their prognostic relevance with regard to reduced progression free survival (PFS) and overall survival (OS) has previously been demonstrated $[17,18,19,20,21]$. In addition, we demonstrated that patients with a marked increase of DTCs after platinum-based chemotherapy showed a significantly reduced PFS [22].

Based on the studies mentioned above, there is increasing evidence that DTCs could reflect cancer progression. Thus, DTCs could be used as novel targets for additional therapeutic strategies. In this study, we analyzed whether our previously reported negative prognostic influence of DTCs with regard to reduced PFS and OS 1) was related to the persistence of DTCs after platinum based chemotherapy and/or 2) might have arisen from a cellular phenotype showing stem cell characteristics.

\section{RESULTS}

\section{Detection of DTCs}

Before therapy (BT), DTCs were detected in $33 / 79$ patients $(42 \%)$ with a median number of 4 DTCs (range 1-37). After therapy (AT), 32/79 patients (41\%) were positive for DTCs (median cell number of 8 cells (range 1-100) (Table 1). DTCs were found in 13 patients BT and AT, in 20 patients only BT and in 19 patients only AT, respectively. DTCs were not detected in samples taken BT or AT from 27 patients (Table 2).

\section{Prognostic significance of DTCs}

After a median follow up time of 62 months (range $10-128$ months), 44 patients $(56 \%)$ were still alive and
33 patients $(42 \%)$ had died. The median follow-up time for PFS was 15 months (range 4-87 months) resulting in $53(67 \%)$ relapses while 25 patients $(32 \%)$ had no relapse (Table 1). The presence of DTCs BT significantly correlated with reduced OS $(p=0.02)$ and patients initially

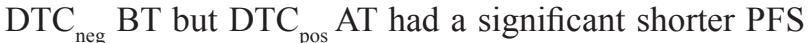
$(p=0.03)$ (Table 2 and Figure 1$)$. The persistence of DTCs resulted in a shorter PFS and OS reaching borderline significance $(p=0.06 ; p=0.07)$.

\section{Evaluation of LIN28- and SOX-2-positive cells}

Staining of patient samples is shown in Figures 2-5. Controls are shown in Supplementary Figures S1-S3. A DTC was classified as a stem-like tumor cell if it had the following staining characteristics: Dapi ${ }_{\text {pos }}, \mathrm{CD} 45_{\text {neg }}$, CD34 ${ }_{\text {neg, }}$ SOX-2 $2_{\text {pos }} / \mathrm{LIN}-28_{\text {pos }}$ and $\mathrm{CK}_{\text {pos }}$ or $\mathrm{CK}_{\text {neg }}$ (Figures 2-5). The Kasumi cell line was used to establish CD34 expression (Supplementary Figure 1) and BM samples from healthy donor patients for CD34- and CD45-expression (Supplementary Figures 2 and 3).

\section{Detection of LIN-28- and SOX-2-positive cells}

DTCs from 10 patients were analyzed BT and AT for SOX-2 and LIN-28 positive cells AT (Table 3; columns 1 and 2; Supplementary Table 1). 8/10 patients had at least five DTCs as detected by immunocytochemistry using A45/B-B3. In addition, 2/10 patients (patient 2 and 5) ${\text { were } \text { DTC }_{\text {neg }} \text { AT but DTC }}_{\text {pos }}$ BT. As apparent from Table 3, AT $\mathrm{CK}_{\text {pos }} / \mathrm{LIN}-28_{\text {pos }}$ cells were detected in 9/10 patients [median 2 cells (range $1-5$ )] and $\mathrm{CK}_{\text {neg }} / \mathrm{LIN}-28_{\text {pos }}$ cells in $7 / 10$ patients [median 3 cells (range $1-11$ )], respectively. $\mathrm{CK}_{\text {pos }} / \mathrm{SOX}-2_{\text {pos }}$ cells were detected in $6 / 8$ patients [median 2 cells (range- $0-4$ ) $]$ and $\mathrm{CK}_{\text {neg }} / \mathrm{SOX}-2_{\text {pos }}$ cells were found in $7 / 8$ patients [median 4 cells (range 1-11)]. Patients two and five, who were characterized as DTC ${ }_{\text {neg }}$ AT by immunocytochemistry but were positive BT (37 and 6 DTCs, respectively) were included in our analysis for stem cell- associated markers. Interestingly, these two patients harbored 1-2 LIN-28 ${ }_{\text {pos }}$ and SOX-2 ${ }_{\text {pos }}$ cells in their BM AT. Thus, we evaluated LIN-28-/SOX-2-positive cells BT in cases vice versa, DTC $_{\text {neg }}$ BT but DTC pos $_{\text {AT (patients } 1,3}$ and 4) as well as in patient number 6 with persistent DTCs. As shown in Table 3, in patients who switched initially DTC $_{\text {neg }}$ before but becoming DTC ${ }_{\text {pos }}$ AT (patients 1, 3 and 4 ), in patients who switched from being DTC $_{\text {pos }}$ before but becoming DTC $_{\text {neg }}$ AT (patients 2 and 5) as well as in patient number 6 with persistent DTCs (patient 6) a few LIN-28 as well as SOX-2-positive cells were present in BM even BT.

\section{DISCUSSION}

To the best of our knowledge, this is the first study showing that DTCs, present after platinum based chemotherapy in primary ovarian cancer patients show 
Table 1: Patient characteristics at the time of primary diagnosis

Total

\begin{tabular}{|l}
\hline Age \\
\hline FIGO stage \\
\hline I-II \\
\hline III \\
\hline IV \\
\hline
\end{tabular}

Nodal status

\begin{tabular}{ll}
$\mathrm{N}_{\mathrm{o}}$ \\
\hline $\mathrm{N}_{1}$ \\
$\mathrm{~N}_{\mathrm{x}}$ \\
\hline
\end{tabular}

Grading

I-II

III

Unknown

Residual tumor

Macroscopic

Complete resection

Any residual tumor

Histologic type

\begin{tabular}{|c|}
\hline Serous \\
\hline Mucinous \\
\hline Other \\
\hline DTC \\
\hline Before therapy \\
\hline After therapy
\end{tabular}

Survival

\begin{tabular}{|l|}
\hline PFS $^{1}$ \\
\hline OS $^{2}$ \\
\hline Alive \\
\hline Dead \\
\hline Unknown \\
\hline Recuren
\end{tabular}

Recurrence

\begin{tabular}{|l|}
\hline No relapse \\
\hline Relapse \\
\hline Unknown \\
\hline
\end{tabular}

Platinum resistance

Platinum sensitive
Platinum resistant

${ }^{1} \mathrm{PFS}$ : progression-free survival, ${ }^{2} \mathrm{OS}$ : overall survival.
79

median 60 years, $(26-86)$

\begin{tabular}{|r|r}
\hline $21(26 \%)$ \\
\hline $48(61 \%)$ \\
\hline $10(13 \%)$
\end{tabular}

$32(40,5 \%)$
$32(40,5 \%)$
$10(19 \%)$

$44(56 \%)$
$33(42 \%)$
$2(2 \%)$

$49(62 \%)$

$30(38 \%)$

$47(60 \%)$
$9(11 \%)$
$23(29 \%)$

median 15 months, (4-87 months)

median 62 months, (10-128 months)

$44(56 \%)$
$33(42 \%)$
$2(2 \%)$

\begin{tabular}{|c|}
\hline $25(32 \%)$ \\
\hline $53(67 \%)$ \\
\hline $1(1 \%)$ \\
\hline
\end{tabular}

$60(76 \%)$

$19(24 \%)$ 
Table 2: Prognostic significance of DTCs before and after therapy with regard to PFS and OS

\begin{tabular}{|c|c|c|c|}
\hline Status & Number of patients $(n)$ & PFS ( $p$-value) & OS (p-value) \\
\hline Total & 79 & & \\
\hline DTC $_{\text {pos }}$ before therapy & 33 & 0.06 & 0.02 \\
\hline $\mathrm{DTC}_{\text {pos }}$ after therapy & 32 & 0.35 & 0.98 \\
\hline $\mathrm{DTC}_{\mathrm{pos}} / \mathrm{DTC}_{\mathrm{pos}}$ & 13 & 0.06 & 0.07 \\
\hline $\mathrm{DTC}_{\text {neg }} / \mathrm{DTC}_{\mathrm{neg}}$ & 27 & 0.77 & 0.31 \\
\hline $\mathrm{DTC}_{\mathrm{pos}} / \mathrm{DTC}_{\mathrm{neg}}$ & 20 & 0.46 & 0.25 \\
\hline $\mathrm{DTC}_{\text {neg }} / \mathrm{DTC}_{\mathrm{pos}}$ & 19 & 0.03 & 0.18 \\
\hline
\end{tabular}

stem cell characteristics. Furthermore, although $p$ values reached borderline significance, these cells might be associated with worse outcome which finally has to be proven in a bigger patient cohort.

The rate of DTC detection in primary ovarian cancer before the administration of platinum-based chemotherapy has been reported to be $20 \%$ to $60 \%$, depending on the method of detection used. Furthermore, their presence has been associated with worse outcome $[17,18,19,20,21,22]$. The lack of significant correlation between DTCs and clinical outcome reported by other investigators may be due to their use of different antibodies for detection of DTCs [23, 24].

In this study, DTCs were present in the BM AT in $41 \%$ of the patients which is in accordance with our earlier data which also demonstrated that DTCs, still present AT, were non-apoptotic and their marked increase was associated with a significantly reduced PFS [22]. These findings suggest that the BM seems may to be a temporary homing site for isolated tumor cells, where they can persist and potentially induce recurrence of the disease. Analyzing 79 patients BT and AT, we confirm the negative prognostic influence of DTC detection with regard to OS [20]. We observed persistent DTCs in 16\% of the patients which was associated with a shorter PFS and OS, reaching borderline significance. Interestingly, $24 \%$ of the patients that were initially characterized as

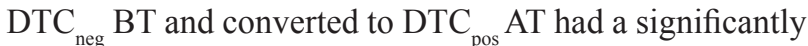
shorter PFS. The negative prognostic influence of these cells could be in alliance with a currently discussed hypothesis that some DTCs may have cancer stem cell features and may be the active source of metastatic spread in primary tumors, in addition to resistance to various chemotherapeutic agents and radiotherapy [25]. Two studies have confirmed a putative stem cell phenotype among DTCs in breast cancer patients [26, 27]. Here, we demonstrate that presence of DTCs that persist AT express the stem cell markers Lin-28 and/or SOX-2. We show that stem cell-like cells were present before the administration of chemotherapy. These findings may explain the significantly shorter PFS of patients who changed from $\mathrm{DTC}_{\text {neg }}$ BT to DTC ${ }_{\text {pos }}$ AT. In addition, patients characterized as $\mathrm{DTC}_{\text {neg }}$ AT also harbored some
Lin-28 and/or SOX-2 positive cells in their BM which may be responsible for a worse outcome. Until now, tumor stem cells have only been analyzed in ovarian tumor tissue, but not in DTCs. In this regard, previous studies have shown that LIN-28, SOX-2 as well as OCT-4 play a major role in carcinogenesis $[10,11,12]$. Wang et al., reported that SOX-2 targets SRC Kinase, a non-receptor tyrosine kinase that increases cell migration, invasion and adhesion of serous ovarian carcinoma cells [13]. Inhibition of either LIN-28 or Oct-4 expression decreases cell viability. The combined repression of both LIN-28 and Oct-4 results in synergistic inhibition of cancer cell growth and survival of ovarian cancer cell lines [9]. Expression of SOX-2 has been investigated by immunohistochemistry analysis of normal ovarian epithelial, serous and mucinous cystadenoma and cystadenomacarcinoma specimens [28] and LIN-28 was overexpressed in different epithelial tumors including breast, lung, colon and ovarian cancer [29]. Furthermore, SOX-2 may be crucial for the development of chemotherapy resistance. Yang et al., analyzed SOX-2 expression in clinical tissue samples and ovarian cancer cell lines using immunohistochemistry and real-time PCR and demonstrated that SOX-2 was overexpressed in paclitaxel-resistant cells [30]. In ovarian cancer patients receiving taxanes, expression of SOX-2 was shown to be correlated with chemotherapy resistance and a shorter PFS whereas patients receiving non-taxane based chemotherapy showed no significant response influence [31]. Since the patients in our study have also received a combined therapy with paclitaxel and carboplatin, it may be possible that SOX-2 expression on DTCs was associated with chemotherapy resistance. However, mechanisms associated with chemotherapy resistance in ovarian cancer still remain unclear. Functionally, primary platinum-resistance, defined as platinum-free treatment interval of less than 6 months observed in up to $20 \%$ of ovarian cancer patients, can be the result of either increased tolerance towards DNA-platinum-adducts or enhanced DNA-repair capacity of tumor cells [32, 33, 34]. In this context, we recently demonstrated that $\mathrm{ERCC} 1_{\text {pos }}$ (excision-repair cross-complementing rodent repair deficiency, complementation group 1 nuclease) circulating 


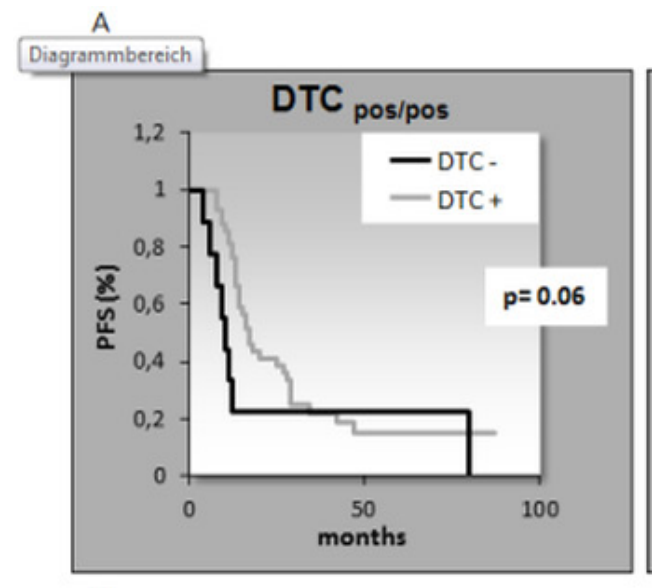

B
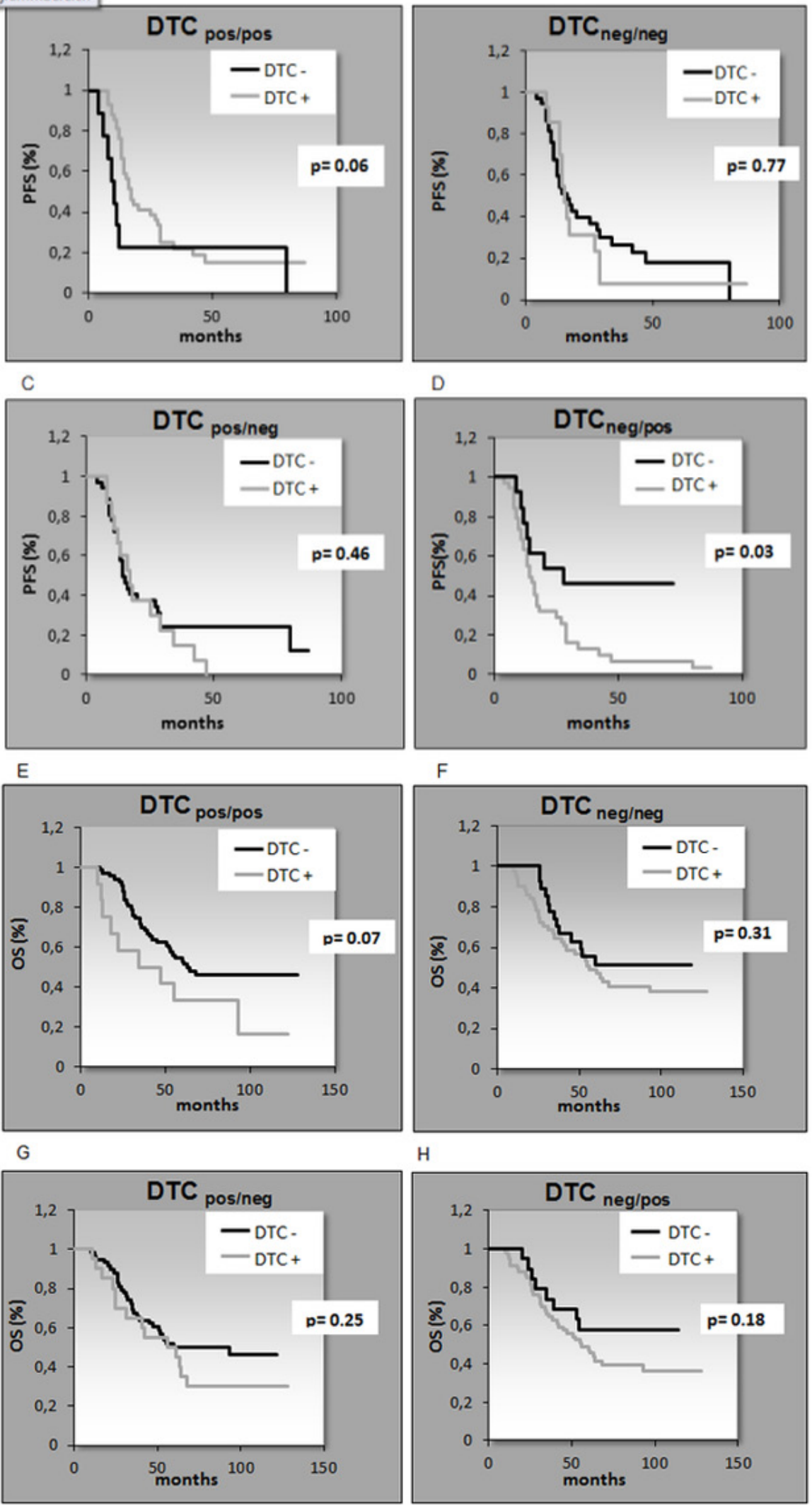

Figure 1: Kaplan-Meier analysis for the correlation of PFS (A-D) and OS (E-H) with DTC detection. Patients initially $\mathrm{DTC}_{\text {neg }}$ before therapy but DTC $\mathrm{pos}_{\text {pos }}$ after therapy had a significant shorter PFS $(p=0.03)$ (Figure 1D). A. PFS DTC $\mathrm{pos}_{\text {poss, }}$ B. PFS DT $\mathrm{T}_{\text {negneg, }}$

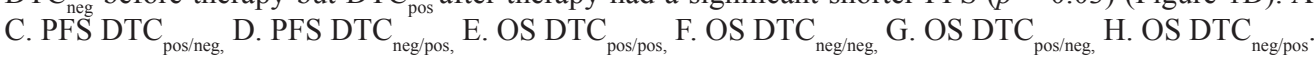


A

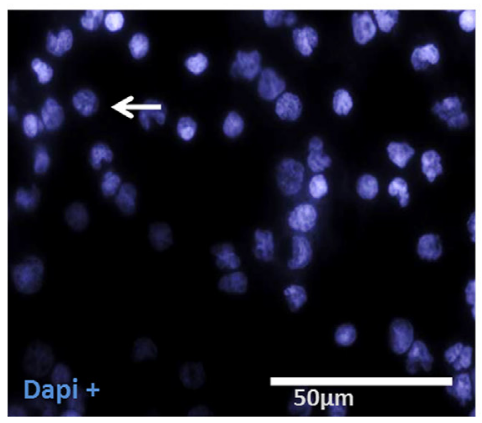

D

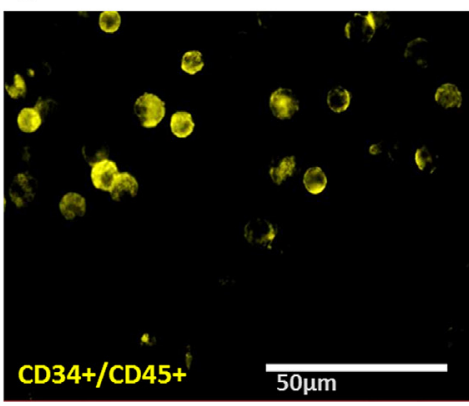

B

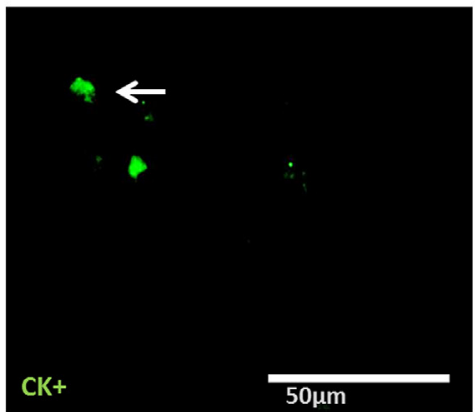

C

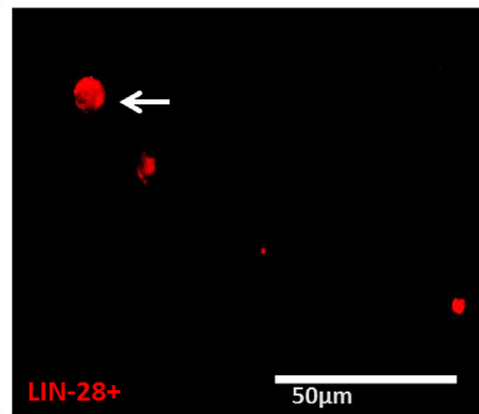

E

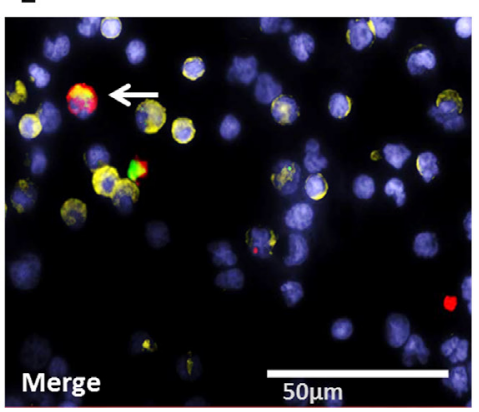

Figure 2: Representative four-fold immunofluorescence staining for $\mathrm{CK}_{\text {pos }} / \mathrm{LIN}-28_{\text {pos }}$ cells after therapy of patient No1. (A) Cell nuclei were stained with Dapi. (B) Indicates a $\mathrm{CK}_{\text {pos }}$ cell. (C) Alludes a cell with LIN-28 ${ }_{\text {pos }}$ phenotype. (D) Shows CD34 ${ }_{\text {pos }}$ and/ or $\mathrm{CD}_{4} 5_{\text {pos }}$ cells. (E) Indicates a merge of a DTC with the phenotype Dapi ${ }_{\text {pos }}, \mathrm{CK}_{\text {pos }}, \mathrm{LIN}-28_{\text {pos }}, \mathrm{CD} 34_{\text {neg }}$ and CD45 $5_{\text {neg, }}$ magnification at $63 \times$.

A

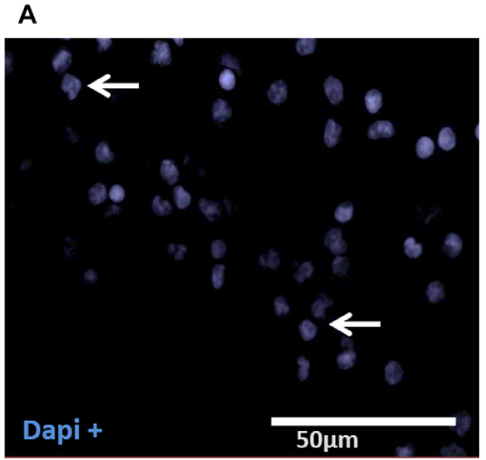

D

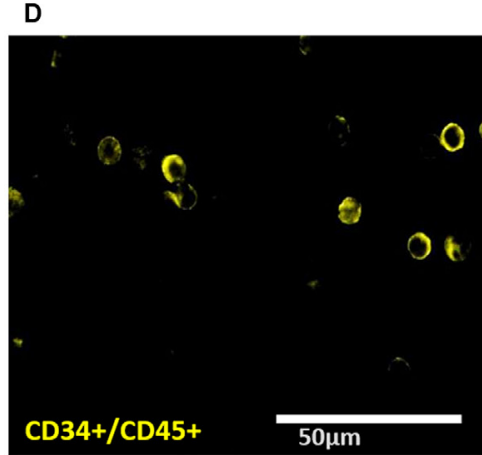

B

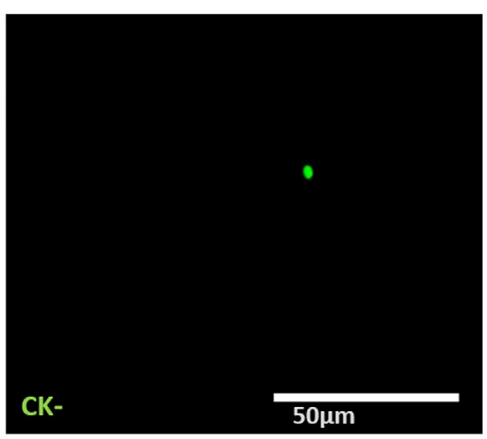

E

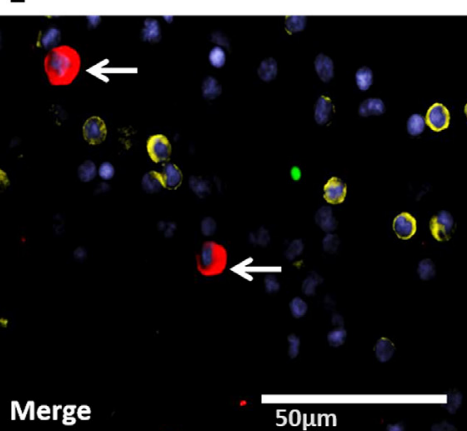

Figure 3: Representative four-fold immunofluorescence staining for $\mathrm{CK}_{\text {neg }} / \mathrm{LIN}-28_{\text {pos }}$ cells after therapy of patient No1. (A) Cell nuclei were stained with Dapi. (B) Indicates a $\mathrm{CK}_{\text {neg }}$ cell. (C) Alludes a cell with LIN-28 ${ }_{\text {pos }}$ phenotype. (D) Shows CD34 ${ }_{\text {pos }}$ and/or CD45 cells. (E) Indicates a merge of two DTCs with the phenotype Dapi ${ }_{\text {pos }}, \mathrm{CK}_{\text {neg, }}, \mathrm{LIN}-28_{\text {pos}}, \mathrm{CD} 34_{\text {neg }}$ and/or CD45 neg, magnification at $63 \times$. 

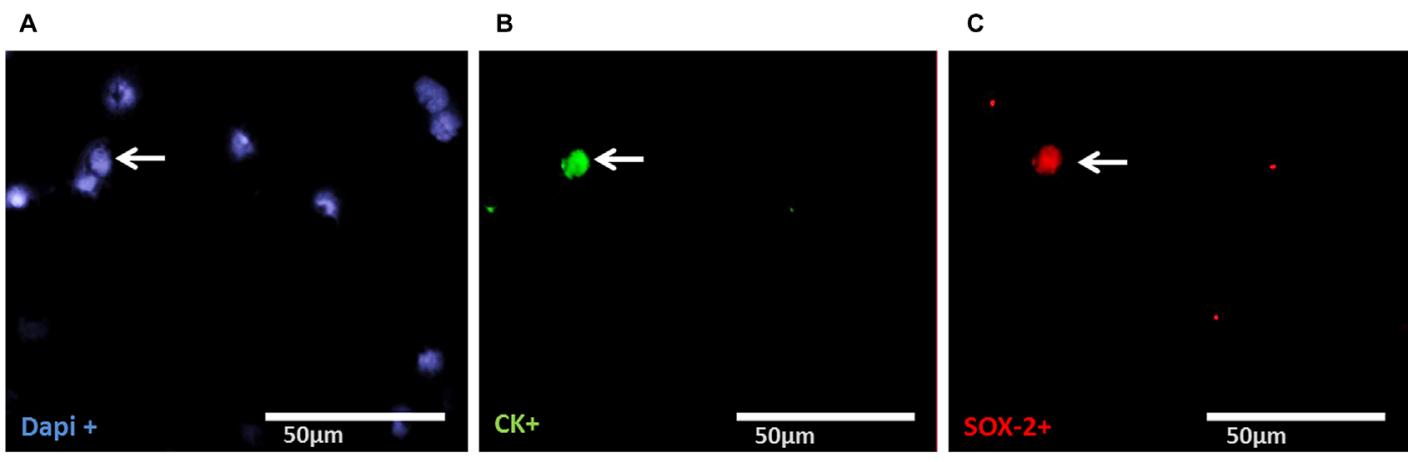

D

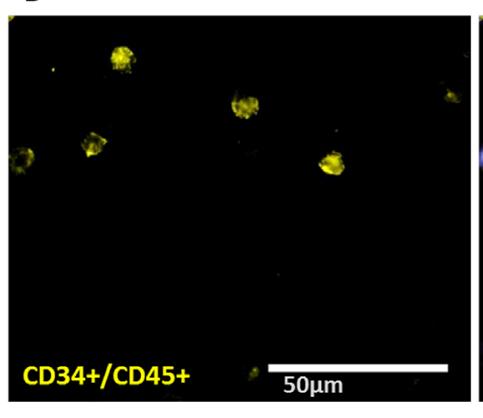

E

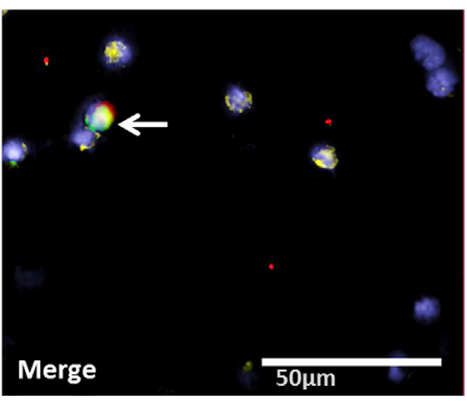

Figure 4: Representative four-fold immunofluorescence staining for $\mathrm{CK}_{\mathrm{pos}} / \mathrm{SOX}-2_{\text {pos }}$ cells after therapy of patient No1. (A)

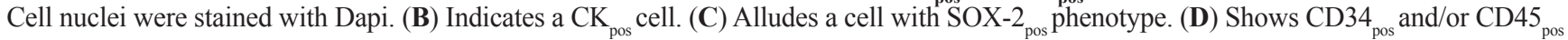
cells. (E) Indicates a merge of a DTC with the phenotype Dapi $i_{\text {pos }}, \mathrm{CK}_{\text {pos }}, \mathrm{SOX}-2_{\text {pos }}, \mathrm{CD} 34_{\text {neg }}$ and/or CD45 $5_{\text {neg, }}$ magnification at $63 \times$.

A

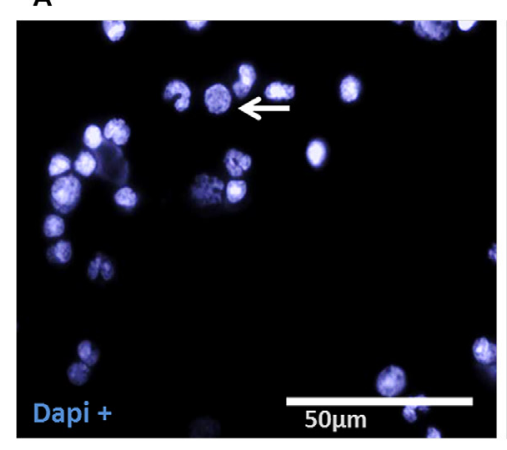

B

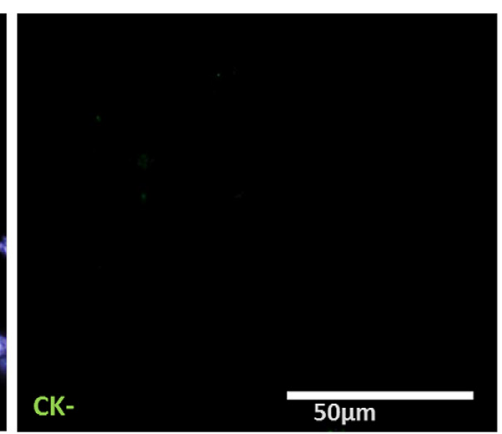

C

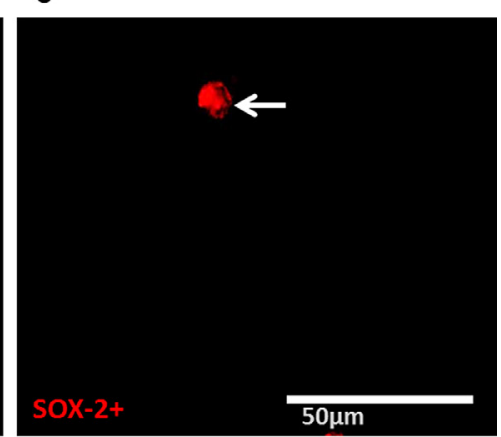

D E
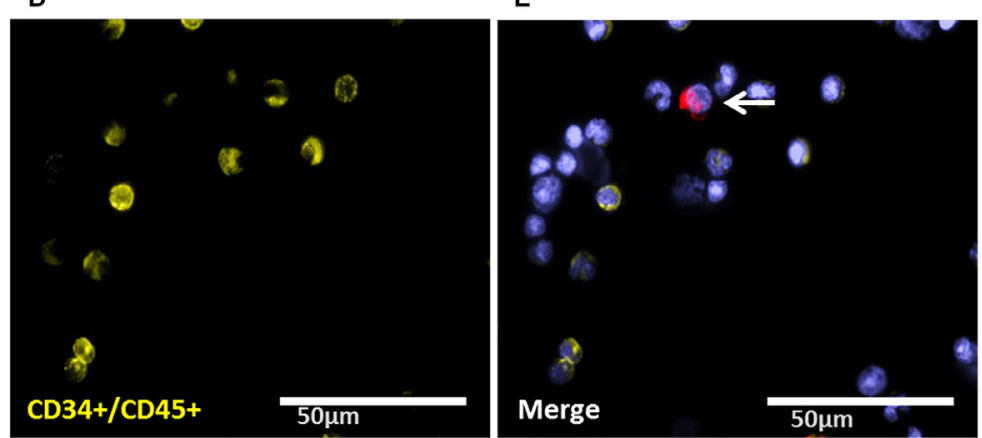

Figure 5: Representative four-fold immunofluorescence staining for $\mathrm{CK}_{\text {neg }} / \mathrm{SOX}-2$ pos cells after therapy of patient No1. (A) Cell nuclei were stained with Dapi. (B) Indicates a $\mathrm{CK}_{\text {neg }}$ cell. (C) Alludes a cell with SOX-2 ${ }_{\text {pos }}$ phenotype. (D) Shows CD34 ${ }_{\text {pos }}$ and/ or $\mathrm{CD} 45_{\text {pos }}$ cells. (E) Indicates a merge of a DTC with the phenotype Dapi pos $, \mathrm{CK}_{\text {neg, }}, \mathrm{SOX}-2_{\text {pos }}, \mathrm{CD} 34_{\text {neg }}$ and $\mathrm{CD} 45_{\text {neg, }}$, magnification at $63 \times$. 
Table 3: Distribution of DTCs and LIN-28-/SOX-2-positive cells before and after therapy

\begin{tabular}{|c|c|c|c|c|c|c|c|c|c|c|}
\hline \multirow[b]{2}{*}{ Patient } & \multirow[b]{2}{*}{$\begin{array}{c}\text { DTC }_{\text {pos }} \text { before } \\
\text { therapy } \\
(\mathbf{A} 45-\mathrm{B} / \mathrm{B} 3)\end{array}$} & \multirow[b]{2}{*}{$\begin{array}{c}\text { DTC }_{\text {pos }} \text { after } \\
\text { therapy } \\
\text { (AF45-B/ } \\
\text { B3) }\end{array}$} & \multicolumn{4}{|c|}{ before therapy } & \multicolumn{4}{|c|}{ after therapy } \\
\hline & & & $\begin{array}{l}\mathrm{CK}_{\text {pos }} \text { ' } \\
\text { LIN- } \\
\mathbf{2 8}{ }_{\text {pos }}\end{array}$ & $\begin{array}{l}\text { CK }_{\text {neg }} \text { ' } \\
\text { LIN- } \\
28_{\text {pos }}\end{array}$ & $\begin{array}{c}\mathrm{CK}_{\mathrm{pos}} / \\
\text { SOX- } \\
\boldsymbol{2}_{\text {pos }}\end{array}$ & $\begin{array}{c}\mathrm{CK}_{\mathrm{neg}}{ }^{\prime} \\
\text { SOX- } \\
\mathbf{2}_{\text {pos }}\end{array}$ & $\begin{array}{c}\mathrm{CK}_{\text {pos }} / \\
\text { LIN- } \\
28_{\text {pos }}\end{array}$ & $\begin{array}{l}\mathrm{CK}_{\text {neg }} / \\
\text { LIN- } \\
28_{\text {pos }}\end{array}$ & $\begin{array}{c}\mathbf{C K}_{\text {pos }} / \\
\text { SOX- } \\
\mathbf{2}_{\text {pos }}\end{array}$ & $\begin{array}{c}\mathrm{CK}_{\mathrm{neg}}{ }^{\prime} \\
\text { SOX- } \\
\mathbf{2}_{\mathrm{pos}}\end{array}$ \\
\hline 1 & 0 & 14 & 25 & 5 & 24 & 2 & 4 & 0 & 3 & 4 \\
\hline 2 & 37 & 0 & 2 & 0 & 4 & 1 & 0 & 1 & 2 & 0 \\
\hline 3 & 0 & 11 & 8 & 2 & 5 & 1 & 2 & 0 & 0 & 1 \\
\hline 4 & 0 & 15 & 2 & 1 & 1 & 1 & 2 & 1 & nsa & nsa \\
\hline 5 & 6 & 0 & 1 & 1 & 2 & 1 & 1 & 0 & 2 & 1 \\
\hline 6 & 28 & 18 & nsa & nsa & 2 & 3 & 3 & 7 & 4 & 11 \\
\hline 7 & 0 & 5 & nsa & nsa & nsa & nsa & 1 & 3 & 0 & 2 \\
\hline 8 & 0 & 100 & nsa & nsa & nsa & nsa & 5 & 9 & 1 & 2 \\
\hline 9 & 1 & 35 & nsa & nsa & nsa & nsa & 2 & 1 & nsa & nsa \\
\hline 10 & 0 & 10 & nsa & nsa & nsa & nsa & 3 & 11 & 2 & 9 \\
\hline
\end{tabular}

nsa: no slides available.

tumor cells (CTCs) constituted an independent predictor, not only for OS but also for PFS in our ovarian cancer patients. Most interestingly, the presence of ERCC $1_{\text {pos }}$ CTCs at primary diagnosis was an independent predictor for platinum-resistance whereas ERCC1-expression in the corresponding primary tumor tissue predicted neither platinum-resistance, nor prognosis [35]. Consequently, assuming that CTCs must be spread into the circulation from existing pools in secondary organs, e.g. the BM, one might speculate that ERCC1 ${ }_{\text {pos }}$ DTCs also exist and contribute to platinum resistance. Interestingly, DTCs present BT in our patients significantly correlated with clinical platinum resistance (data not shown).

In this study, we also detected $\mathrm{CK}_{\text {pos }} / \mathrm{SOX}-2$ pos (LIN-28 $8_{\text {pos }}$ ) as well as $\mathrm{CK}_{\text {neg }} / \mathrm{SOX}-2_{\text {pos }}\left(\mathrm{LIN}-28_{\text {pos }}\right)$ cells in all patients. We assume that two different cell types with expression of stem cell associated proteins may have been detected. It has been described that tumor cells undergo phenotypic changes, known as epithelial-mesenchymal transition (EMT), which allow them to migrate to sites of metastasis without being eliminated by conventional treatment [36]. Thus, $\mathrm{CK}_{\text {neg }} / \mathrm{SOX}-2_{\text {pos }}\left(\mathrm{Lin}-28_{\text {pos }}\right)$ cells might result from EMT while the $\mathrm{CK}_{\text {pos }} / \mathrm{SOX}-2_{\text {pos }}$ (LIN-28 $8_{\text {pos }}$ ) epithelial phenotype may have remained unchanged.

Taking all these considerations into account, additional therapeutic strategies will be required to target signaling pathways concerning CSC. These studies will include mTOR inhibitors, acting downstream of the PI3K/ AKT pathway [37], salinomycin [38] or a new synthetic curcumin analogue against ALDH1 and GSK-3ß [39]. Finally, approaching the tumor microenvironment, such as interrupting the immune cells and cytokines (e.g. IL-6, IL-8) as well as the immune checkpoints (PD1/PDL1) may provide additional new tools for immunological killing of cancer stem cells $[40,41,42]$

\section{Conclusion and limitation of the study}

The cohort of our patients is probably too small to draw the final conclusion that a significant selection of stem cell marker-positive DTCs occurs during chemotherapy. Consequently, the results presented here should be viewed as a "proof of principle", that DTCS with stem cell characteristics exist among DTCs that are present BT and persist AT. To the best of our knowledge, we are the only group that has a collection of BM cells harvested from primary ovarian cancer patients AT. In this regard, 79 paired samples from patients who consented to allow collection of their BM under local anesthesia AT for research purposes is a unique collection and would be difficult to achieve high patient numbers. Furthermore, based on the number of residual slides and methodological requirements, we only analyzed two stem cell markers. Ongoing studies will include other stem cell markers, such as OCT4 as well as resistance marker to finally elucidate the prognostic relevance of these cells.

\section{PATIENTS AND METHODS}

\section{Patient characteristics}

79 patients with primary ovarian cancer who presented at the Department of Gynecology and Obstetrics, University Hospital Essen between February 2004 and January 2010 were included in this analysis. Patient characteristics are documented in Table 1. The mean age was 60 years (range $26-86$ years), the median follow-up time was 62 months (10-128 months) for OS and 15 months (4-87 months) for PFS. Written Informed consent was obtained from all patients and the study was approved by the Local Ethics Committee (05-2870). Tumors were classified according to the 
WHO classification of tumors of the female genital tract. Grading was conducted using the grading system proposed by Silverberg [43] and tumor staging was classified according to the Fédération Internationale de Gynécology et d'Obstétrique (FIGO 2009). The entire study population underwent primary radical surgery. Total abdominal hysterectomy, bilateral salpingo-oophorectomy, infragastric omentectomy, peritoneal stripping was performed and in addition to pelvic and para-aortic lymphadenectomy, if macroscopic complete resection was achieved. The most important aim of surgery was to achieve macroscopic complete tumor resection. Radical pelvic and para-aortic lymphadenectomy were only performed if complete tumor resection was achieved intraperitoneally following actual guidelines (www.ago-ovar.de). All patients received at least six cycles of carboplatinum AUC 5 and paclitaxel $175 \mathrm{mg} / \mathrm{m} 2$. Tumors were clinically defined as platinum-resistant if they recurred within six months after the completion of platinum-based chemotherapy.

\section{Cell lines}

The human ovarian cancer cell line OVCAR-3 and the Kasumi-1 cell line were purchased from the American Type Culture Collection (ATCC, Manassas, VA, USA) and cultured in RPMI 1640 containing $10 \%$ (20\% for Kasumi-1) fetal calf serum and $1 \%$ (100 U/ml) Penicillin-Streptomycin (Gibco ${ }^{\mathrm{TM}}$ by Thermo Fisher Scientific, Waltham MA, US) . Cells were grown at $37^{\circ} \mathrm{C}$ in a humidified atmosphere with $5 \% \mathrm{CO}$.

\section{Detection of DTCs}

Between 10 and $20 \mathrm{ml} \mathrm{BM}$ were aspirated from the anterior iliac crests and processed within 24 hours. DTC selection and detection was performed based on the recommendations for standardized tumor cell detection [44]. Details of the staining procedure and cell detection have been described elsewhere [22]. Briefly, BM cells were isolated from heparinized BM (5000 U/ml BM) by Ficoll-Hypaque density gradient centrifugation (density $1.077 \mathrm{~g} / \mathrm{mol}$; Pharmacia, Freiburg, Germany) at $400 \times \mathrm{g}$ for $30 \mathrm{~min}$. Slides were analyzed for DTCs by immunocytochemistry using the pan-cytokeratin antibody A45-B/B3. Microscopic evaluation of the slides $\left(1 \times 10^{6}\right.$ mononuclear cells per slide $)$ was carried out using the ARIOL system (Applied Imaging) according to the ISHAGE evaluation criteria [45].

\section{Detection of LIN-28- and SOX-2-positive cells}

LIN-28- and SOX-2 positive cells were analyzed separately on additional slides of the same patients harboring at least five DTCs as detected by immunocytochemistry using the A45B-B3. Four-fold immunofluorescence staining was established using the OVCAR-3 cell line spiked into blood of healthy donors. Since CD34-positive normal hematopoietic stem cells comprise $1.5 \%$ of marrow mononuclear cells [46], we included CD34 in our analysis to exclude false-positive results. CD34 was analysed using the Kasumi-1 cell line since BM of healthy donors was difficult to obtain and only available from one donor (Supplementary Figure 1).

Slides were fixed with $4 \%$ Paraformaldehyde for $10 \mathrm{~min}$, permeabilized with $0.1 \%$ Triton-X-100 for $15 \mathrm{~min}$ and subsequently washed with TBS and Triton-X-100 three times for five min. Slides were stained with SOX-2 (Anti-human SOX-2, 1:50, R \& D Systems, USA), LIN-28 (LIN-28, 1:350, Rabbit polyclonal ab46020, Abcam, UK), C11 (anti-PAN-Cytokeratin, 1:400, FITC-labelled, GeneTex, USA), CD34 (Alexa Flour anti-human 647, 1:100, Cy5 labelled, Biolegend, USA) and CD45 (Alexa Fluor 647;sc1178 Santa Cruz, USA) incubated in a wet chamber for one hour at room temperature. Subsequently, slides were incubated with DAPI [pre diluted in Phosphate Buffered Saline (1:250) and further diluted in AB diluent (1:20, Dako, Germany)], and TRITC-labelled donkey anti-goat 594 (SOX-2), donkey anti-rabbit 594 (LIN-28) (both1:100, Invitrogen, USA) under the same conditions followed by three washing steps for five minutes. Moreover, negative controls for primary antibodies were prepared by staining the spiked OVCAR-3 cell line with the secondary antibodies for 30 minutes under the same conditions. The slides were mounted with Dako fluorescent mounting medium s3023 and a coverslip and dried overnight in a cooling chamber. Counting was performed visually, using an immunofluorescence microscope (Axioplan 2 Imaging Zeiss Germany, Metasystems) and Isis Fish imaging system V5.3 (Meta Systems, Germany) at a magnification of $40 \times$ or $63 \times$.

\section{Statistical analysis}

Survival analysis was performed by using Winstat (2012.1) an upgrade of Microsoft Excel. Survival intervals were screened from the time of BM aspiration at first diagnosis to the time of death or first time of relapse, defined as either local recurrence or distant metastasis. Kaplan-Meier curves were established using the log-rank test to evaluate univariate significance of the parameters.

\section{CONFLICTS OF INTEREST}

None.

\section{REFERENCES}

1. Goodman M.T, Howe HL, Tung KH, Hotes J, Miller B.A, Coughlin SS, Chen VW. Incidence of ovarian cancer by race, ethnicity in the United States, 1992-1997. Cancer. 2003; 97:2676-2685. 
2. Du Bois A, Pfisterer J. Future options for first-line therapy of advanced ovarian cancer. Int J Gynecol Cancer. 2005; $1: 42-50$.

3. du Bois A, Reuss A, Pujade-Lauraine E, Harter P, Ray-Coquard I, Pfisterer J. Role of surgical outcome as prognostic factor in advanced epithelial ovarian cancer: a combined exploratory analysis of 3 prospectively randomized phase 3 multicenter trials: by the Arbeitsgemeinschaft Gynaekologische Onkologie Studiengruppe Ovarialkarzinom (AGO-OVAR) and the Groupe d'Investigateurs Nationaux Pour les Etudes des Cancers de l'Ovaire (GINECO). Cancer. 2009; 115:1234-44.

4. Wimberger P, Lehmann N, Kimmig R, Burges A, Meier W, Du Bois A; Arbeitsgemeinschaft Gynaekologische Onkologie Ovarian Cancer Study Group. Prognostic factors for complete debulking in advanced ovarian cancer and its impact on survival. An exploratory analysis of a prospectively randomized phase III study of the Arbeitsgemeinschaft Gynaekologische Onkologie Ovarian Cancer Study Group (AGO-OVAR). Gynecol Oncol. 2007; 106:69-74.

5. Wimberger $P$, Wehling $M$, Lehmann N, Kimmig R, Schmalfeldt B, Burges A, Harter P, Pfisterer J, du Bois A. Influence of residual tumor on outcome in ovarian cancer patients with FIGO stage IV disease: an exploratory analysis of the AGO-OVAR (Arbeitsgemeinschaft Gynaekologische Onkologie Ovarian Cancer Study Group). Ann Surg Oncol. $2010 ; 17: 1642-8$.

6. Dyall S, Gayther SA, Dafou D. Cancer stem cells and epithelial ovarian cancer. J. Oncol. 2010; 2010:105269.

7. Hosonuma S, Kobayashi Y, Kojo S, Wada H, Seino KI, Kiguchi K, Ishizuka B. Clinical significance of side population in ovarian cancer cells.Hum Cell. 2011; 24:9-12.

8. Boesch M, Zeimet, AG, Reimer D, Schmidt S, Parson W, Spoeck F, Hatina J, Wolf D, Sopper S. The side population of ovarian cancer cells defines a heterogeneous compartment exhibiting stem cell characteristics. 2014; 5:7027-39.

9. Bapat SA, Koppikar CB, Kurrey NK. Stem and Progenitor-Like Cells Contribute to the Aggressive Behavior of Human Epithelial Ovarian Cancer.Cancer Res. 2005; 65:3025-3029.

10. Peng S, Maihle NJ, Huang Y. Pluripotency factors Lin28 and Oct4 identify a sub-population of stem cell-like cells in ovarian cancer. Oncogene. 2010; 29:2153-5159.

11. Bareiss PM, Paczulla A, Wang H, Schairer R, Wiehr S, Kohlhofer U, Rothfuss OC, Fischer A, Perner S, Staebler A, Wallwiener D, Fend F, Fehm T, et al. SOX2 expression associates with stem cell state in human ovarian carcinoma. Cancer Res. 2013; 73; 5544-5555.

12. Pham D. Scheble V, Bareiss P, Fischer A, Beschorner C, Bachmann C, Neubauer H, Boesmueller H, Kanz L. SOX2 in ovarian carcinoma - association with high grade and improved outcome after platinum-based chemotherapy. Int J Gynecol Pathol. 2013; 32:358-67.

13. Wang X, Ji X, Chen J, Yan D, Zhang Z, Wang Q, Xi X, Feng Y. SOX2 Enhances the Migration and Invasion of
Ovarian Cancer Cells via Src Kinase. PLoS One. 2014; 9:e9959414.

14. Lou X, Han X, Jin C, Tian W, Yu W, Ding D, Cheng L, Huang B, Jiang H, Lin B. SOX2 targets fibronectin 1 to promote cell migration and invasion in ovarian cancer: new molecular leads for therapeutic intervention. OMICS. 2013; 17:510-8.

15. Li Y, Chen K. Li L, Li R, Zhang J, Ren W. Overexpression of $\mathrm{SOX} 2$ is involved in paclitaxel resistance of ovarian cancer via the PI3K/Akt pathway. Tumour Biol. 2015; 36:9823-8.

16. Du J, Li B, Fang Y, Liu Y, Wang Y, Li J, Zhou W, Wang X. Overexpression of Class III $\beta$-tubulin, Sox2, and nuclear Survivin is predictive of taxane resistance in patients with stage III ovarian epithelial cancer. BMC Cancer. 2015; 15:536.

17. Banys M, Solomayer EF, Becker S, Krawczyk N, Gardanis K, Staebler A, Neubauer H, Wallwiener D, Fehm T. Disseminated tumor cells in bone marrow may affect prognosis of patients with gynecologic malignancies. Int $\mathbf{J}$ Gynecol Cancer. 2009; 19:948-52.

18. Braun S, Schindlbeck C, Hepp F, Janni W, Kentenich C, Riethmüller G, Pantel K. Occult tumor cells in bone marrow of patients with locoregionally restricted ovarian cancer predict early distant metastatic relapse. J Clin Oncol. 2001; 19:368-375.

19. Romero-Laorden N, Olmos D, Fehm T, Garcia-Donas J, Diaz-Padilla I. Circulating and disseminated tumor cells in ovarian cancer: A systematic review. Gynecol Oncol. 2014; 133:632-9.

20. Fehm T, Banys M, Rack B, Janni W, Marth C, Blassl C, Hartkopf A, Trope C, Kimmig R, Krawczyk N, Wallwiener D, Wimberger P, Kasimir-Bauer S. Pooled analysis of the prognostic relevance of disseminated tumor cells in the bone marrow of patients with ovarian cancer. Int J Gynecol Cancer. 2013; 23:839-845.

21. Cui L, Kwong J, Wang CC. Prognostic value of circulating tumor cells and disseminated tumor cells in patients with ovarian cancer: a systematic review and meta-analysis. Journal of Ovarian Research. 2015; 8:38.

22. Wimberger P, Heubner M, Otterbach F, Fehm T, Kimmig R, Kasimir-Bauer S. Influence of platinum-based chemotherapy on disseminated tumor cells in blood and bone marrow of patients with ovarian cancer. Gynecol. Oncol. 2007; 107, 331-338.

23. Marth C, Kisic J, Kaern J, Tropé C, Fodstad Ø. Circulating tumor cells in the peripheral blood and bone marrow of patients with ovarian carcinoma do not predict prognosis. Cancer. 2002; 94:707-712.

24. Cain JM, Ellis GK, Collins C, Greer BE, Tamimi HK, Figge DC, Gown AM, Livingston RB. Bone marrow involvement in epithelial ovarian cancer by immunocytochemical assessment. Gynecol Oncol. 1990; 38: 442-445.

25. Monteiro J, Fodde R. Cancer stemness and metastasis: therapeutic consequences and perspectives. Eur J Cancer. 2010; 46:1198-203. 
26. Balic M, Lin H, Young L, Hawes D, Giuliano A, McNamara G, Datar RH, Cote RJ. Most early disseminated cancer cells detected in bone marrow of breast cancer patients have a putative breast cancer stem cell phenotype. Clin Cancer Res. 2006; 12:5615-5621.

27. Reuben JM, Lee BN, Gao H, Cohen EN, Mego M, Giordano A, Wang X, Lodhi A, Krishnamurthy S, Hortobagyi GN, Cristofanilli M, Lucci A, Woodward WA. Primary breast cancer patients with high risk clinicopathologic features have high percentages of bone marrow epithelial cells with ALDH activity and CD44 ${ }^{+} \mathrm{CD} 241$ o cancer stem cell phenotype. Eur J Cancer. 2011; 47:1527-36.

28. Ye F, Li Y, Hu Y, Zhou C, HU Y, Chen H. Expression of Sox2 in human ovarian epithelial carcinoma. J Cancer Res Clin Oncol. 2011; 137:131-7.

29. Viswanathan SR, Powers JT, Einhorn W, Hoshida Y, Ng TL Toffanin S, O'Sullivan M, Lu J, Phillips LA, Lockhart VL, Shah SP, Tanwar PS, Mermel CH, et al. Lin28 promotes transformation and is associated with advanced human malignancies. Nat Genet. 2009; 41:843-8.

30. Li Y, Chen K, Li L, Li R, Zhang J, Ren W. Overexpression of Sox2 is involved in paclitaxel resistance of ovarian cancer via the PI3K/AKT pathway. Tumour Biol. 2015; 36:9823-8.

31. Du J, Li B, Fang Y, Liu Y, Wang Y, Li J, Zhou W, Wang X. Overexpression of Class III ß-tubulin, Sox2, and nuclear surviving is predictive of taxane resistance in patients with stage III ovarian epithelial cancer. BMC Cancer. 2015; 15:536.

32. Johnson NP, Hoeschele JD, Rahn RO. Kinetic analysis of the in vitro binding of radioactive cis-and trans-dichlorodiammineplatinum (II) to DNA. Chem Biol Interact. 1980; 30:151-69.

33. Bookman Michael A. Extending the Platinum-free Interval in Recurrent Ovarian Cancer: The role of Topeka in Second-Line Chemotherapy. The Oncologist. 1999; 4:87-94.

34. Galluzzi L, Senovilla L, Vitale I, Michels J, Martins I, Kepp O, Castedo M, Kroemer G. Molecular mechanism of cisplatin resistance. Oncogene. 2012; 31:1869-183.

35. Kuhlmann JD, Wimberger P, Bankfalvi A, Keller T, Schöler S, Aktas B, Buderath P, Hauch S, Otterbach F, Kimmig R, Kasimir-Bauer S. ERCC1-positive circulating tumor cells in the blood of Ovarian cancer patients as a predictive biomarker for platinum resistance. Clinical Chemistry. 2014; 60:10 1282-1289.

36. Chiara F, Massimo B, Daniele G, Giovanna D. Epithelialmesenchymal transition and breast cancer: Role, molecular mechanisms and clinical impact. Cancer treatment Reviews. 2012; 38:689-97.
37. Zhang J, Zhang XB, Liu Y, Liu JJ, Zhang MS. Effects of an mTOR inhibitor RAD001 on human breast cancer stem cells in vitro and in vivo. J Clin Oncol. 2011. 29:abstr e11514.

38. Gupta PB, Onder TT, Jiang G, Tao K, Kuperwasser C, Weinberg RA, Lander ES. Identification of selective inhibitors of cancer stem cells by high-throughput screening. Cell. 2009; 138:645-659.

39. Kesharwani RK, Srivastava V, Singh P, Rizvi SI, Adeppa K, Misra K. A novel approach for overcoming drug Resistance in breast cancer chemotherapy by targeting new synthetic curcumin analogues against aldehyde dehydrogenase 1 (ALDH1A1) and glycogen synthase kinase-3 B (GSK-3ß). Appl Biochem Biotechnol. 2015; 176:1996-2017.

40. Pan Q, Li Q, Liu S, Ning N, Zhang X, Xu Y, Chang AE, Wicha MS: targeting cancer stem cells using immunologic approaches. Stem Cells. 2015; 33:2085-2092.

41. Sharma P, Wagner K, Wolchok JD, Allison JP. Novel cancer immunotherapy agents with survival benefit: Recent successes and next steps. Nat Rev Cancer. 2011; 11:805-812.

42. Topalian SL, Hodi FS, Brahmer JR, Gettinger SN, Smith DC, McDermott DF, Powderly JD, Carvajal RD, Sosman JA, Atkins MB, Leming PD, Spigel DR, Antonia SJ, et al. Safety, activity, and immune correlates of anti-PD-1 antibody in cancer. N Engl J Med. 2012; 366:2443-2454.

43. Silverberg SG. Histopathologic grading of ovarian carcinoma: a review and proposal. Int J Gynecol Pathol. 2000; 19:7-15.

44. Fehm T, Braun S, Muller V, Janni W, Gebauer G, Marth C, Schindlbeck C, Wallwiener D, Borgen E, Naume B, Pantel K, Solomayer E. A concept for the standardized detection of disseminated tumor cells in bone marrow of patients with primary breast cancer and its clinical implementation. Cancer. 2006; 107:885-92.

45. Borgen E, Naume B, Nesland JM, Kvalheim G, Beiske K, Fodstad O, Diel I, Solomayer EF, Theocharous P, Coombes R, Smith BM, E Wunder, Marolleau JP, et al. Standardization of the immunocytochemical detection of cancer cells in BM and blood: I. Establishment of objective criteria for the evaluation of immunostained cells: The European ISHAGE Working Group for Standardization of Tumor Cell Detection. Cytotherapy. 1999; 5:377-388.

46. Krause DS, Fackler MJ, Civin CI, May WS. CD34: structure, biology, and clinical utility. Blood. 1996, 1:87: 1-13. 